\title{
Midline Suboccipital Subtonsillar Approach in Semisitting Position for Resection of Jugular Tubercle Meningioma: 2-Dimensional Operative Video
}

\author{
Stefan Lieber ${ }^{1,2}$ Maximiliano Nunez ${ }^{2}$ Marcos Tatagiba ${ }^{1}$ \\ ${ }^{1}$ Department of Neurological Surgery, Eberhard-Karls-University, \\ University Hospital Tübingen, Germany \\ 2 Department of Neurological Surgery, Microsurgical Neuroanatomy \\ Lab, University of Pittsburgh, Pennsylvania, United States \\ Address for correspondence Stefan Lieber, MD, Department of \\ Neurological Surgery, Eberhard-Karls-University, \\ Hoppe-Seyler-Strasse 3, D-72076 Tübingen, Germany \\ (e-mail: Stefan.Lieber@uclmail.net).
}

J Neurol Surg B 2021;82(suppl S1):S48-S50.

\begin{abstract}
We present a case of a large jugular tubercle meningioma that was removed through a midline suboccipital subtonsillar approach in semisitting position. The patient is a 49-yearold woman with chronic, medication-resistant cephalgias but devoid of any subjective focal neurological deficit. On magnetic resonance imaging (MRI), an extra-axial lesion, originating from the left jugular tubercle was discovered. There was significant obliteration of the peripontine cisternal space, and compression of the adjacent pontomedullary junction; the lesion also extended into the left jugular foramen.

On physical exam, an absent gag reflex was noted on the left, as well as a moderate deviation of the uvula to the contralateral side (partial Vernet's syndrome).

A gross-total resection was achieved, histopathology confirmed a World Health Organization (WHO) grade I angiomatous meningioma with a low-proliferation index. The patient was discharged home 4 days after surgery with intact function of the lower cranial nerves (CN) following immediate and complete resolution of the preexisting partial CNs IX and X deficits. At 2-year follow-up, there was no indication of intradural residual or recurrence.

Keywords

- suboccipital subtonsillar approach

- jugular tubercle

- meningioma

- jugular foramen

- semisitting position

- operative video

In summary, the midline suboccipital subtonsillar approach is a simple and effective tool with limited morbidity in the armamentarium for the microsurgical management of pathologies residing in the posterior cranial fossa or the craniocervical junction. Major limitations exist for lesions extending above the internal acoustic canal or those of fibrous consistence featuring widespread adhesion to the ventral brainstem or vascular encasement. Provided the necessary anesthesiological precautions and intraoperative procedures the semisitting position is safe and effective. The link to the video can be found at: https://youtu.be/bbVXagwhDCo.
\end{abstract}

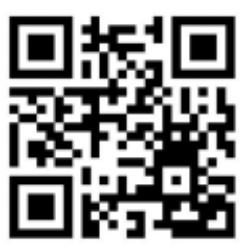

www.thieme.com/skullbasevideos

www.thieme.com/jnlsbvideos

received

May 12, 2019

accepted after revision

January 22, 2020

published online

November 26, 2020
DOI https://doi.org/ 10.1055/s-0040-1705165. ISSN 2193-6331.

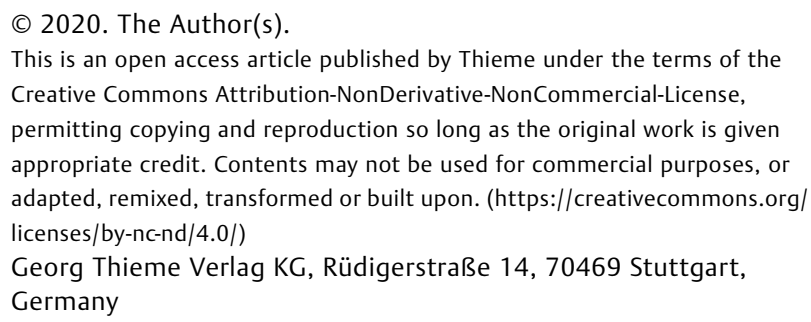




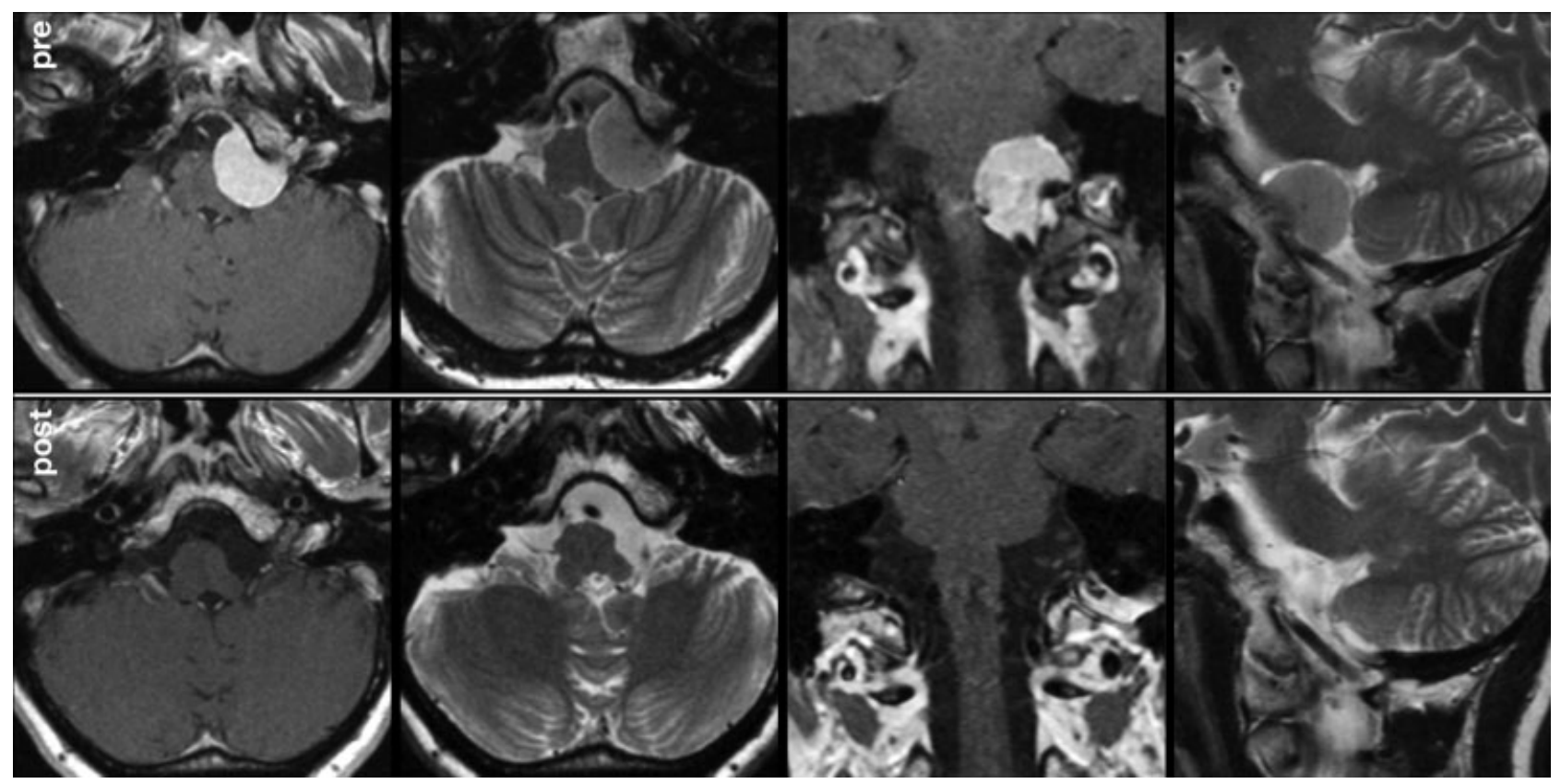

Fig. 1 Pre- and postoperative MRI studies of the meningioma which originates from the left jugular tubercle, occupies substantial cisternal space, and compresses the adjacent pontomedullary junction. MRI, magnetic resonance imaging.

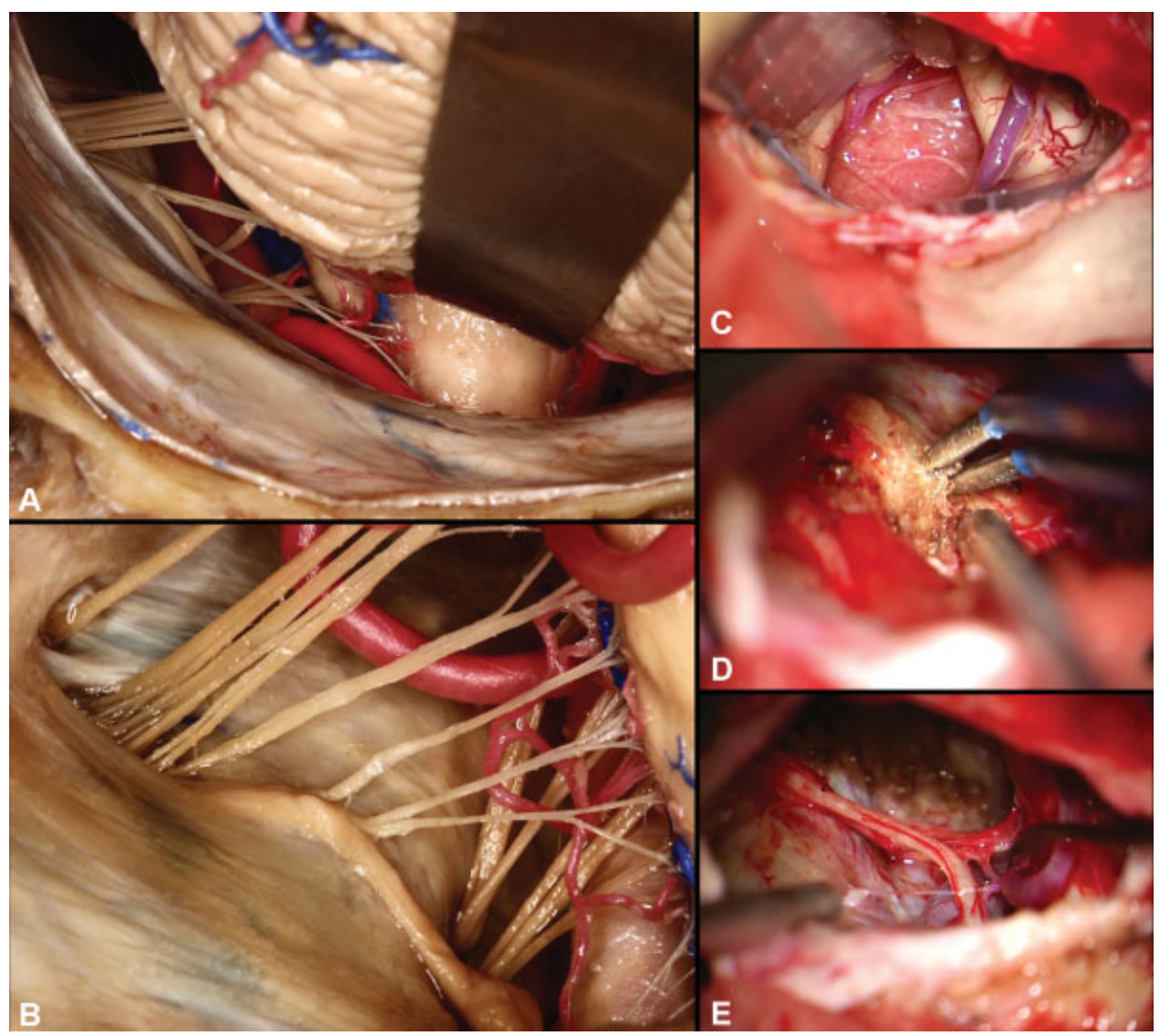

Fig. 2 Anatomical dissections (fixed, silicone-injected human cadaver): (A) left-sided suboccipital subtonsillar approach, (B) neurovascular structures around the jugular foramen and the hypoglossal canal. Operative still images of a left-sided suboccipital subtonsillar approach: (C) between the cerebellar tonsil and the medulla the meningioma is visualized, (D) bipolar coagulation of the dural attachment on the jugular tubercle, (E) after complete microsurgical excision with preservation of the adjacent neurovascular structures, here the combined craniospinal trunk of the accessory nerve and the telovelotonsillar segment of the posterior inferior cerebellar artery (PICA). 


\section{Disclosures}

None. The authors have no personal, institutional, or financial interest in any of the materials, drugs, or devices described in this article.

\section{Conflict of Interest}

None declared.

\section{References}

1 Dobrowolski S, Ebner F, Lepski G, Tatagiba M. Foramen magnum meningioma: The midline suboccipital subtonsillar approach. Clin Neurol Neurosurg 2016;145:28-34

2 Herlan S, Ebner FH, Nitz A, Hirt B, Tatagiba M, Roser F. The midline suboccipital subtonsillar approach to the cerebellomedullary cistern and its structures: anatomical considerations, surgical technique and clinical application. Clin Neurol Neurosurg 2014;125:98-105 